\title{
Distribution of metastatic disease in the brain in relation to the hippocampus: a retrospective single-center analysis of 6064 metastases in 632 patients
}

\author{
San-Gang Wu ${ }^{1,},{ }^{*}$ Ming-Yue Rao ${ }^{2,}{ }^{*}$, Juan Zhou ${ }^{3, *}$, Qin Lin ${ }^{1}$, Zi-Jing Wang ${ }^{1}$, Yong-Xiong \\ Chen ${ }^{4}$, Zhen-Yu He ${ }^{5}$ \\ ${ }^{1}$ Department of Radiation Oncology, Xiamen Cancer Center, the First Affiliated Hospital of Xiamen University, Xiamen, \\ People's Republic of China \\ ${ }^{2}$ Department of Radiology, the First Affiliated Hospital of Xiamen University, Xiamen, People's Republic of China \\ ${ }^{3}$ Department of Obstetrics and Gynecology, Xiamen Cancer Center, the First Affiliated Hospital of Xiamen University, Xiamen, \\ People's Republic of China \\ ${ }^{4}$ Eye Institute of Xiamen University, Fujian Provincial Key Laboratory of Ophthalmology and Visual Science, Medical College \\ of Xiamen University, Xiamen, People's Republic of China \\ ${ }^{5}$ Department of Radiation Oncology, Sun Yat-sen University Cancer Center, State Key Laboratory of Oncology in South China, \\ Collaborative Innovation Center of Cancer Medicine, Guangzhou, People's Republic of China \\ *These authors have contributed equally to this work \\ Correspondence to: \\ Yong-Xiong Chen, e-mail: yxchen1962@xmu.edu.cn \\ Zhen-Yu He, e-mail: hezhy@sysucc.org.cn \\ Keywords: metastatic brain tumor, hippocampus, whole brain radiation therapy, age \\ Received: June 12, $2015 \quad$ Accepted: October 09, $2015 \quad$ Published: October 19, 2015
}

\section{ABSTRACT}

This study aimed to investigate the patterns of brain metastasis and to explore the risk factors affecting hippocampus metastasis (HM). We retrospectively analyzed the clinical information of patients with metastatic disease in the brain. The associations between clinicopathologic variables with HM and peri-hippocampal metastasis (PHM) were evaluated in univariate and multivariate regression analyses. A total of 632 patients with 6064 metastatic lesions were recruited into the present study. Of these, $4.1 \%(26 / 632)$ of patients developed HM, and 5.5\% (35/632) of patients developed PHM. Only $0.5 \%(31 / 6064)$ of metastatic lesions were located in the hippocampus and $0.6 \%(37 / 6064)$ were in the PHM. Age $\leq 60$ years was an independent risk factor for HM (odds ratio [OR]: 2.602, 95\% confidence interval [CI]: 1.115-6.076, $P=0.027$ ) and PHM (OR: 2.555, 95\%CI: 1.229-5.310, $P=0.012$ ) in univariate and multivariate analyses. The hippocampus is a rare site of brain metastasis. Younger patients (age $\leq 60$ years) had increased risk of developing HM and PHM. The current study provides the opportunity to investigate the clinical feasibility of hippocampal sparing whole brain radiation therapy, especially in older patients.

\section{INTRODUCTION}

Approximately $10 \%$ to $80 \%$ of patients with malignancies may develop brain metastases from different primary tumor sites [1-4], and there are associated with a dismal prognosis. Whole brain radiotherapy may attenuate the symptoms of brain metastasis and prolong survival time [5]. Moreover, for patients with non-small cell lung cancer (NSCLC) or small cell lung cancer (SCLC), survival can be improved by prophylactic cranial irradiation (PCI) $[6,7]$. However, whole brain radiotherapy may cause neurocognitive decline and significantly affect the quality of life (QOL) [8]. Radiation-induced damage to the hippocampus plays a considerable role in the neurocognitive decline of patients after whole brain radiotherapy [9].

The hippocampus, which is a neural structure located in the medial temporal lobe of the brain, has highly sensitive to radiation [10]. Studies have shown that the incidence of hippocampal metastasis (HM) is 
rarely compared to other sites [11-14], and these results support the hypothesis that hippocampal radiotherapy should be avoided. The Radiation Therapy Oncology Group (RTOG) 0933 trial found that hippocampal sparing whole brain radiation therapy (HS-WBRT) could lessen the effect of radiation on memory [15]. However, not all patients are suitable for HS-WBRT. Currently, an accurate tool to predict hippocampal metastasis is lacked. In this study, we analyzed the distribution of metastatic disease in the brain in patients with malignancies and further explored the factors influencing metastasis to the hippocampus.

\section{RESULTS}

A total of 632 patients met the inclusion criteria were retrospectively analyzed. Table 1 summarized the clinicopathologic characteristics of these patients. The median age at diagnosis was 61 years (range, 20-93 years). There were 395 men (62.5\%). NSCLC was found in $64.9 \%$ $(n=410)$ of patients, SCLC in $8.0 \%(n=51)$ of patients, and breast cancer in $8.9 \%(n=56)$ of patients. Moreover, there were $4.1 \%(26 / 632)$ of patients with HM and 5.5\% (35/632) with peri-hippocampal metastasis (PHM).

Among the 632 patients, there were 6064 metastases and the median number of metastases was 3 (range, 1-223). The distribution of metastases is shown in Table 2. The frontal lobe was the most common site of metastases $(31.6 \%, 1919 / 6064)$, followed by parietal lobe $(18.3 \%$,
$1110 / 6064)$, cerebellum $(18.1 \%, 1098 / 6064)$, occipital lobe $(13.0 \%, 786 / 6064)$, temporal lobe $(11.7 \%, 708 / 6064)$ and brain stem $(6.8 \%, 412 / 6064)$. Thirty-one metastases were within the hippocampus $(0.5 \%, 31 / 6064)$ (Figure 1), and 37 metastases were within the peri-hippocampal region $(0.6 \%, 37 / 6064)$. The mean hippocampus volume was $4.7 \mathrm{~cm}^{3}$ (range, $3.6-6.6 \mathrm{~cm}^{3}$ ). On average, hippocampal avoidance region occupied $2.1 \%$ (range, $1.7 \%-2.9 \%$ ) of the whole brain volume (Table 3).

The univariate and multivariate logistic regression analysis indicated that age was an independent risk factor for HM and PHM. Patients with age $\leq 60$ years had a higher risk with HM (odds ratio [OR]: 2.602, 95\% confidence interval $[\mathrm{CI}]: 1.115-6.076, P=0.027)$ and PHM (OR: 2.555, 95\% CI: 1.229-5.310, $P=0.012$ ) than those with age $>60$ years (Tables 4 and 5 ). Of the 26 patients with HM, 18 patients were $\leq 60$ years old. The median number of brain metastases was 19 (range, 2-174), and the median number of brain metastases was 24 (range, $7-47$ ) in 8 patients with age $>60$ years.

With potential increased risk of $\operatorname{HM}(P=0.078)$ in breast cancer patients compared to NSCLC patients in univariate analysis, therefore, the risk of HM and PHM of breast cancer in comparison with other tumors were analyzed. Among patients with breast cancer, the risk of HM was greater than that in patients with other cancers, but there was no statistical significance (OR: 2.591, 95\%CI: 0.938-7.161, $P=0.066$ ) and PHM (OR: 2.263, 95\%CI: $0.897-5.711, P=0.084)$, and the results were not affected by the age in breast cancer patients $(P>0.05)$.

Table 1: Clinicopathological characteristics of patients with metastatic brain tumors $(n=632)$

\begin{tabular}{l}
\hline Characteristics \\
\begin{tabular}{|l|c|}
\hline Age (years) & $\boldsymbol{n}(\%)$ \\
\hline$\leq 60$ & $299(47.3)$ \\
\hline$>60$ & $333(52.7)$ \\
\hline Sex & $395(62.5)$ \\
\hline Male & $237(37.5)$ \\
\hline Female & \\
\hline Primary site & $410(64.9)$ \\
\hline Non-small-cell lung cancer & $51(8.0)$ \\
\hline Small-cell lung cancer & $56(8.9)$ \\
\hline Breast & $22(3.4)$ \\
\hline Colorectal & $14(2.2)$ \\
\hline Stomach & $27(4.3)$ \\
\hline Esophagus & $15(2.4)$ \\
\hline Liver & $37(5.9)$ \\
\hline Other & \\
\hline
\end{tabular}
\end{tabular}


Table 2: The distribution of metastases by location $(n=6064)$

\begin{tabular}{l}
\hline Location \\
\begin{tabular}{|l|c|}
\hline Parietal lobe & $\boldsymbol{n}(\mathbf{\%})$ \\
\hline Frontal lobe & $1110(18.3)$ \\
\hline Temporal lobe* & $1919(31.6)$ \\
\hline Occipital lobe & $708(11.7)$ \\
\hline Cerebellum & $786(13.0)$ \\
\hline Brainstem & $1098(18.1)$ \\
\hline Hippocampus & $412(6.8)$ \\
\hline Total & $31(0.5)$ \\
\hline
\end{tabular}
\end{tabular}

*Exclusion of metastases involved in hippocampus

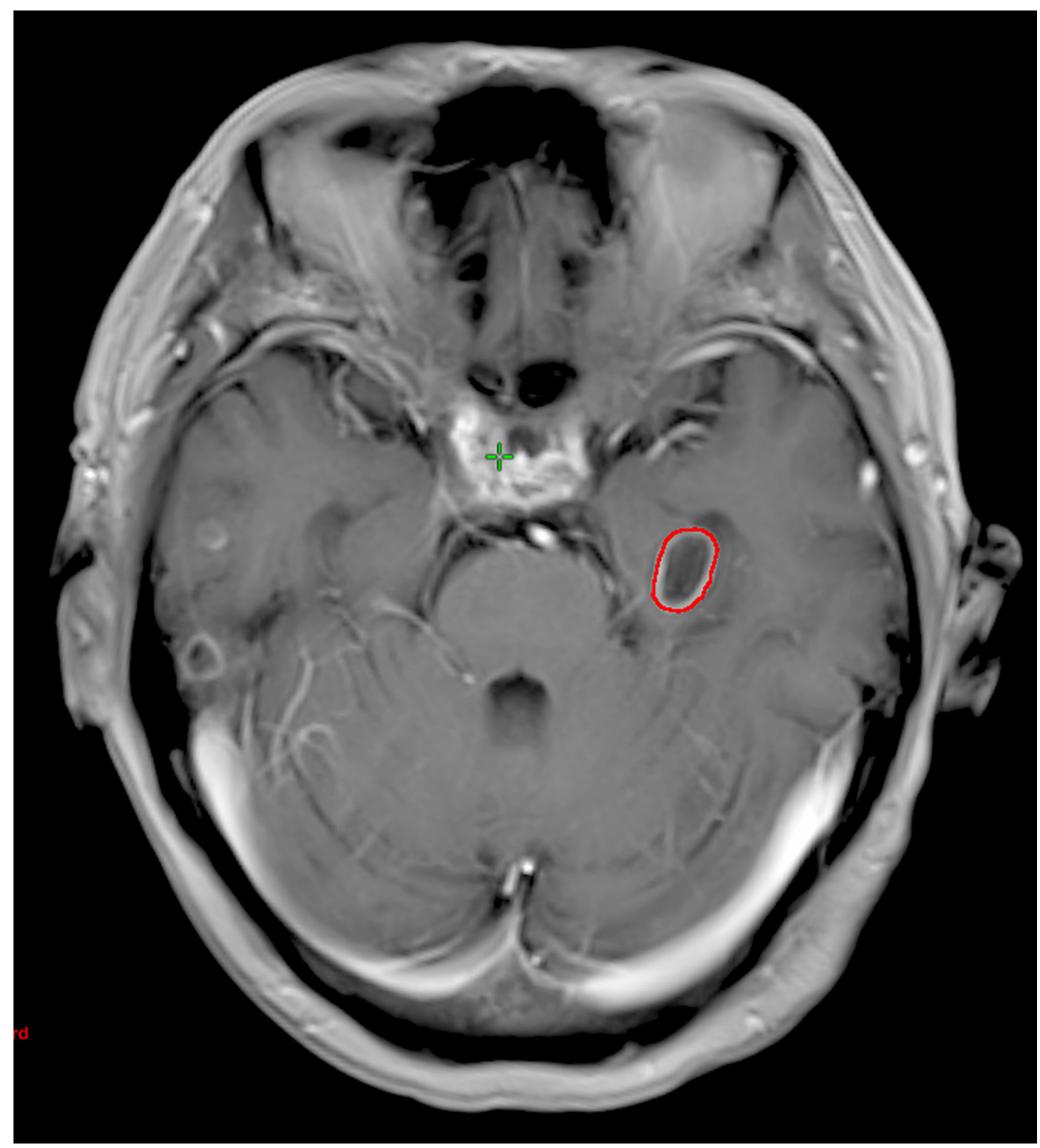

Figure 1: Magnetic resonance image of a patient who has a hippocampal metastasis. The red contour represents the hippocampal metastasis. 
Table 3: Average volume of hippocampus and hippocampal avoidance regions relateive to the whole brain

\begin{tabular}{c|c|c|c|}
\hline $\begin{array}{c}\text { Hippocampus } \\
\text { volume, } \\
\mathbf{c m}^{3}\end{array}$ & $\begin{array}{c}\text { Hippocampal avoidance } \\
\text { volume, } \\
\mathbf{c m}^{\mathbf{3}}\end{array}$ & $\begin{array}{c}\text { Whole brain } \\
\text { volume, } \\
\mathbf{c m}^{3}\end{array}$ & $\begin{array}{c}\text { Percentage of whole brain } \\
\text { occupied by hippocampal } \\
\text { avoidance region }\end{array}$ \\
\hline $4.7 \pm 1.0$ & $28.4 \pm 4.1$ & $1366.3 \pm 160.0$ & $2.1 \pm 0.4$ \\
\hline
\end{tabular}

Table 4: Univariate logistic regression of hippocampus metastasis and peri hippocampus metastasis

\begin{tabular}{|c|c|c|c|c|c|c|}
\hline \multirow[t]{2}{*}{ Characteristics } & \multicolumn{3}{|c|}{ Hippocampus metastasis } & \multicolumn{3}{|c|}{ Peri hippocampus metastasis } \\
\hline & OR & $95 \% \mathrm{CI}$ & $\boldsymbol{P}$ & OR & $95 \% \mathrm{CI}$ & $\boldsymbol{P}$ \\
\hline \multicolumn{7}{|l|}{ Age (years) } \\
\hline$>60$ & 1 & & & 1 & & \\
\hline$\leq 60$ & 2.602 & $1.115-6.076$ & 0.027 & 2.555 & $1.229-5.310$ & 0.012 \\
\hline \multicolumn{7}{|l|}{ Sex } \\
\hline Male & 1 & & & 1 & & \\
\hline Female & 0.686 & $0.312-1.509$ & 0.349 & 0.695 & $0.350-1.379$ & 0.298 \\
\hline \multicolumn{7}{|l|}{ Primary site } \\
\hline NSCLC & 1 & & & 1 & & \\
\hline SLCL & 1.646 & $0.460-5.892$ & 0.444 & 1.102 & $0.318-3.820$ & 0.878 \\
\hline Breast & 2.582 & $0.900-7.402$ & 0.078 & 2.116 & $0.819-5.470$ & 0.122 \\
\hline Other & 0.705 & $0.201-2.480$ & 0.586 & 0.636 & $0.215-1.883$ & 0.413 \\
\hline
\end{tabular}

OR, odds ratio; CI, confidence interval; NSCLC, non-small cell lung cancer; SCLC, small cell lung cancer.

Table 5: Multivariate logistic regression of hippocampus metastasis and peri hippocampus metastasis

\begin{tabular}{|c|c|c|c|c|c|c|}
\hline \multirow[t]{2}{*}{ Characteristics } & \multicolumn{3}{|c|}{ Hippocampus metastasis } & \multicolumn{3}{|c|}{ Peri hippocampus metastasis } \\
\hline & OR & $95 \% \mathrm{CI}$ & $\boldsymbol{P}$ & OR & $95 \% \mathrm{CI}$ & $\boldsymbol{P}$ \\
\hline \multicolumn{7}{|l|}{ Age (years) } \\
\hline$>60$ & 1 & & & 1 & & \\
\hline$\leq 60$ & 2.602 & $1.115-6.076$ & 0.027 & 2.555 & $1.229-5.310$ & 0.012 \\
\hline \multicolumn{7}{|l|}{ Sex } \\
\hline Male & 1 & & & 1 & & \\
\hline Female & 1.070 & $0.412-2.778$ & 0.889 & 1.073 & $0.478-2.407$ & 0.864 \\
\hline \multicolumn{7}{|l|}{ Primary site } \\
\hline NSCLC & 1 & & & 1 & & \\
\hline SLCL & 1.677 & $0.466-6.041$ & 0.429 & 1.120 & $0.321-3.906$ & 0.859 \\
\hline Breast & 1.988 & $0.676-5.849$ & 0.212 & 1.626 & $0.615-4.299$ & 0.327 \\
\hline Other & 0.723 & $0.205-2.551$ & 0.641 & 0.651 & $0.219-1.935$ & 0.440 \\
\hline
\end{tabular}

OR, odds ratio; CI, confidence interval; NSCLC, non-small cell lung cancer; SCLC, small cell lung cancer. 


\section{DISCUSSION}

In the present study, we retrospectively analyzed 632 patients with 6064 metastases resulting from extracranial malignancies. Our results showed that the incidence of HM and PHM was rarely $(4.1 \%$ and $5.5 \%$, respectively), and the risk for HM (OR: 2.602) and PHM (OR: 2.555) increased significantly in patients with age $\leq 60$ years.

With advances in imaging and more effective systemic treatments improving survival of cancer patients, the probability of brain metastases maybe potentially increase. PCI may benefit patients with NSCLC or SCLC [6,7]. However, it is imperative to balance therapeutic efficacy with the risk of radiotherapyinduced damage to the brain. Studies have confirmed that hippocampal radiotherapy may cause neurocognitive decline $[8,9]$. In patients receiving brain radiotherapy, the dose of radiation to the hippocampus and temporal lobe may significantly influence cognitive function of patients [19]. The RTOG 0933 trial employed intensitymodulated radiation therapy (IMRT) for HS-WBRT, and the results showed that this technique could significantly improve memory and QOL [15].

In patients with metastatic disease in the brain or those receiving PCI, the decision to perform HS-WBRT is determined by the incidence of HM. Gondi et al. investigated 371 patients with 1133 metastases, and their results showed that $8.6 \%$ of patients had PHM, which accounted for $3 \%$ of metastases. However, no patient had HM [11]. Harth et al. investigated 100 patients with 856 metastases, and found that $3 \%$ patients with HM ( $0.4 \%$ of metastases) [12]. Of 100 patients with 272 metastases, Ghia et al. found that $8 \%$ of patients had PHM, which were $3.3 \%$ of metastases [13]. In a study of Chinese patients, Wan et al. investigated 488 patients with 2270 metastases, and the results revealed that $1.4 \%$ of patients had HM $(0.3 \%$ of metastases [14]. In the present study, we investigated 632 patients with 6064 metastases, HM and PHM were found in 4.1\% and $5.5 \%$ of patients, and accounted for $0.5 \%$ and $0.6 \%$ of metastases, respectively. These percentages are consistent with those previously reported. In addition, no studies have been conducted with Chinese patients with brain metastases to assess the effects of HSWBRT. Although the present study was retrospective review, it is feasible to implement HS-WBRT for Chinese population. Furthermore, it is now technically and dosimetrically feasible to implement HS-WBRT approaches within clinical practice $[15,16,22]$.

In the RTOG 0933 trial, $4.5 \%$ of patients developed HM after HS-WBRT [15], while in a study by Oehlke et al., HM recurred in $10 \%$ of patients after HS-WBRT [17]. Although there is a potential risk of HM or PHM after HS-WBRT, it is important to develop tools to accurately predict HM or PHM. In a study of SCLC, Kundapur et al. found that the number of metastatic lesions was potentially related to HM (OR: 1.4, 95\% CI: 0.9-2.2, $P=0.09$ ) [18]. In the study by Oehlke et al., $10 \%(2 / 20)$ of patients developed new HM after HS-WBRT, and new HM occurred concomitantly with multiple other new lesions and not as isolated relapses. However, these lesions were not described in detail [17].

In this study, we found that advancing age was an independent risk factor of HM and PHM. The relationship between HM or PHM and age is unclear. However, studies have found that older age is a poor prognostic factor for survival in patients with metastatic disease in the brain [23-26]. The survival of younger patients with metastatic disease in the brain have a longer life expectancy, and the probability of progression of brain metastases may potentially increase, thereby increasing the probability of HM and PHM. In this study, we found patients with HM are often accompanied by the multiple brain metastases. However, due to the limitations of retrospective studies, we are unable to accurately obtain the time of brain metastases and HM.

Currently, the correlation between specific primary tumor site (including SCLC, NSCLS and melanoma, etc.) and the HM remains unclear [12, 18, 20, 21]. In our study, the risk for HM and PHM in patients with breast cancer was greater than that of patients with other types of cancers, but with no statistical significance. Given that the incidence of HM is very low, it is very difficult to use the type of cancer as to guide to determine whether this procedure is necessary.

There were several limitations to the present study. First, this is a retrospective review from single institution. However, to the best of our knowledge, this study had the largest sample size and our results are similar to other studies. Second, our results are absent the data of HM and PHM after whole brain radiotherapy.

In conclusion, the hippocampus is a rare site of brain metastasis. Patients with younger age had increased risk of developing HM and PHM. The current study provides the opportunity to investigate the clinical feasibility of HSWBRT, especially in older patients

\section{PATIENTS AND METHODS}

\section{Patients}

Patients were retrospectively reviewed from the First Hospital of Xiamen University between January 2008 and March 2015. These patients were pathologically diagnosed with extracranial malignancies and had brain metastases at initial diagnosis or follow up. The results of magnetic resonance imaging (MRI) including T1weighted, postcontrast, and axial MRI images were available for all patients. The study protocol was approved by the ethics committee of the First Affiliated Hospital of Xiamen University. 

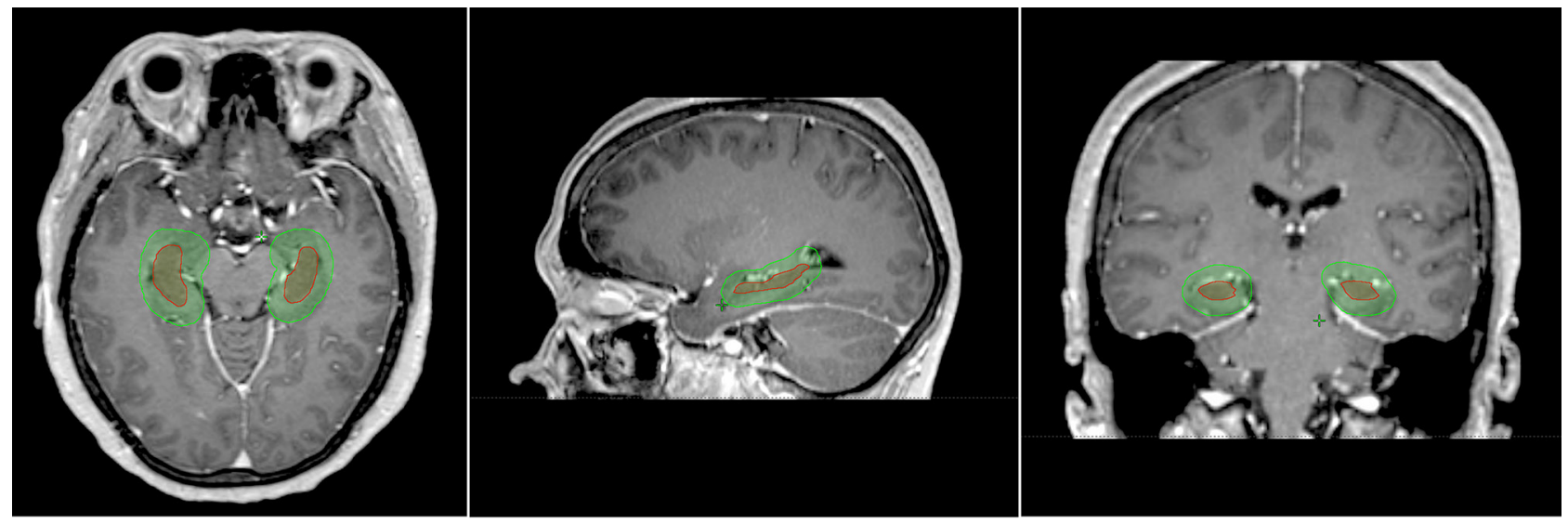

Figure 2: Hippocampus contoured on axial, sagittal, and coronal contrast-enhanced T1 magnetic resonance images. The red contour showing the hippocampus contoured and the hippocampal avoidance region contoured in green.

\section{Delineation of the hippocampus}

In T1 weighted MRI images, the hippocampus was delineated in accordance with the procedures reported in RTOG 0933. Because of the possibility of errors and displacement during radiotherapy, the methods reported by Gondi et al. and Ghia et al. were also used. The hippocampus plus a $5-\mathrm{mm}$ margin was designated as the peri-hippocampal region (Figure 2) $[13,16]$. After delineation of the hippocampus, the distribution of the lesions was documented depending on the location of the lesion from the hippocampus.

\section{Predictive factors}

Age, sex and primary site of malignancy were employed as the risk factors of HM and PHM.

\section{Statistical analysis}

All data were analyzed by using the SPSS statistical software package (version 16.0; IBM Corporation, Armonk, NY, USA). The $\chi^{2}$ test and the Fisher's exact probability test was used for categorical variables and analysis of variance for continuous variables to compare the distribution of demographic data among patients with and without HM and PHM. The relationship between patients' characteristics of $\mathrm{HM}$ and PHM were examined by univariate and multivariate logistic regression analysis. A $P$-value $<0.05$ was considered significant in all analyses.

\section{ACKNOWLEDGMENTS AND FUNDING}

This work was supported by grants from the National Natural Science Foundation of China (No. 81402527), the Sci-Tech Office of Guangdong Province (No. 2013B021800157), the Youth Foundation of Fujian Provincial Health and Family Planning
Commission (No. 2014-2-63), and the Natural Science Foundation of Fujian Province (No. 2015J01550).

\section{CONFLICTS OF INTEREST}

The authors have declared that no competing interests exist.

\section{REFERENCES}

1. Owonikoko TK, Arbiser J, Zelnak A, Shu HK, Shim H, Robin AM, Kalkanis SN, Whitsett TG, Salhia B, Tran NL, Ryken T, Moore MK, Egan KM, Olson JJ. Current approaches to the treatment of metastatic brain tumours. Nat Rev Clin Oncol. 2014; 11:203-222.

2. Taillibert S, Le Rhun É. [Epidemiology of brain metastases]. [Article in French] Cancer Radiother. 2015; 19:3-9.

3. Nugent JL, Bunn PA Jr, Matthews MJ, Ihde DC, Cohen MH, Gazdar A, Minna JD. CNS metastases in small cell bronchogenic carcinoma: increasing frequency and changing pattern with lengthening survival. Cancer. 1979; 44:1885-1893.

4. Wikman H, Westphal L, Schmid F, Pollari S, Kropidlowski J, Sielaff-Frimpong B, Glatzel M, Matschke J, Westphal M, Iljin K, Huhtala H, Terracciano L, Kallioniemi A, Sauter G, Müller V, Witzel I, Lamszus K, Kemming D, Pantel K. Loss of CADM1 expression is associated with poor prognosis and brain metastasis in breast cancer patients. Oncotarget. 2014; 5:3076-3087.

5. Sahgal A, Soliman H, Larson DA. Whole-brain radiation therapy of brain metastasis. Prog Neurol Surg. 2012; 25:82-95.

6. Slotman B, Faivre-Finn C, Kramer G, Rankin E, Snee M, Hatton M, Postmus P, Collette L, Musat E, Senan, S EORTC Radiation Oncology Group and Lung Cancer Group. Prophylactic cranial irradiation in extensive small-cell lung cancer. N Engl J Med. 2007; 357:664-672. 
7. Li N, Zeng ZF, Wang SY, Ou W, Ye X, Li J, He XH, Zhang BB, Yang H, Sun HB, Fang Q, Wang BX. Randomized phase III trial of prophylactic cranial irradiation versus observation in patients with fully resected stage IIIA-N2 non small-cell lung cancer and high risk of cerebral metastases after adjuvant chemotherapy. Ann Oncol. 2015; 26:504-509.

8. Li J, Bentzen SM, Li J, Renschler M, Mehta MP. Relationship between neurocognitive function and quality of life after whole-brain radiotherapy in patients with brain metastasis. Int J Radiat Oncol Biol Phys. 2008; 71:64-70.

9. Gondi V, Tomé WA, Mehta MP. Why avoid the hippocampus? A comprehensive review. Radiother Oncol. 2010; 97:370-376.

10. Kempf SJ, Moertl S, Sepe S, von Toerne C, Hauck SM, Atkinson MJ, Mastroberardino PG, Tapio S. Low-dose ionizing radiation rapidly affects mitochondrial and synaptic signaling pathways in murine hippocampus and cortex. J Proteome Res. 2015; 14:2055-2064.

11. Gondi V, Tome WA, Marsh J, Struck A, Ghia A, Turian JV, Bentzen SM, Kuo JS, Khuntia D, Mehta MP. Estimated risk of perihippocampal disease progression after hippocampal avoidance during whole-brain radiotherapy: safety profile for RTOG 0933. Radiother Oncol. 2010; 95:327-331.

12. Harth S, Abo-Madyan Y, Zheng L, Siebenlist K, Herskind C, Wenz F, Giordano FA. Estimation of intracranial failure risk following hippocampal-sparing whole brain radiotherapy. Radiother Oncol. 2013; 109:152-158.

13. Ghia A, Tomé WA, Thomas S, Cannon G, Khuntia D, Kuo JS, Mehta MP. Distribution of brain metastases in relation to the hippocampus: implications for neurocognitive functional preservation. Int J Radiat Oncol Biol Phys. 2007; 68:971-977.

14. Wan JF, Zhang SJ, Wang L, Zhao KL. Implications for preserving neural stem cells in whole brain radiotherapy and prophylactic cranial irradiation: a review of 2270 metastases in 488 patients. J Radiat Res. 2013; 54:285-291.

15. Gondi V, Pugh SL, Tome WA, Caine C, Corn B, Kanner A, Rowley H, Kundapur V, DeNittis A, Greenspoon JN, Konski AA, Bauman GS, Shah S, Shi W, Wendland M, Kachnic L, Mehta MP. Preservation of memory with conformal avoidance of the hippocampal neural stem-cell compartment during whole-brain radiotherapy for brain metastases (RTOG 0933): a phase II multi-institutional trial. J Clin Oncol. 2014; 32:3810-3816.

16. Gondi V, Tolakanahalli R, Mehta MP, Tewatia D, Rowley H, Kuo JS, Khuntia D, Tomé WA. Hippocampalsparing whole-brain radiotherapy: a "how-to" technique using helical tomotherapy and linear accelerator-based intensity-modulated radiotherapy. Int J Radiat Oncol Biol Phys. 2010; 78:1244-1252.

17. Oehlke O, Wucherpfennig D, Fels F, Frings L, Egger K, Weyerbrock A, Prokic V, Nieder C, Grosu AL. Whole brain irradiation with hippocampal sparing and dose escalation on multiple brain metastases : Local tumour control and survival. Strahlenther Onkol. 2015; Jan 16: 10.1007/s00066014-0808-9 25592907. [Epub ahead of print].

18. Kundapur V, Ellchuk T, Ahmed S, Gondi V. Risk of hippocampal metastases in small cell lung cancer patients at presentation and after cranial irradiation: a safety profile study for hippocampal sparing during prophylactic or therapeutic cranial irradiation. Int J Radiat Oncol Biol Phys. 2015; 91:781-786.

19. Redmond KJ, Mahone EM, Terezakis S, Ishaq O, Ford E, McNutt T, Kleinberg L, Cohen KJ, Wharam M, Horska A. Association between radiation dose to neuronal progenitor cell niches and temporal lobes and performance on neuropsychological testing in children: a prospective study. Neuro Oncol. 2013; 15:360-369.

20. Hong AM, Suo C, Valenzuela M, Haydu LE, Jacobsen KD, Reisse CH, Fogarty G. Low incidence of melanoma brain metastasis in the hippocampus. Radiother Oncol. 2014; 111:59-62.

21. Witt J, Pluard TJ, Ferraro DJ, Jaboin JJ, Thomas MA, Zoberi I, Robinson CG. A study of the anatomic distribution of brain metastases in HER2+ breast cancer: Implications for hippocampal avoidance PCI. J Clin Oncol 32, 2014 (suppl; abstr e11578).

22. Rong Y, Evans J, Xu-Welliver M, Pickett C, Jia G, Chen Q, Zuo L. Dosimetric evaluation of intensity-modulated radiotherapy, volumetric modulated arc therapy, and helical tomotherapy for hippocampal-avoidance whole brain radiotherapy. PLoS One. 2015; 10:e0126222.

23. Nam BH, Kim SY, Han HS, Kwon Y, Lee KS, Kim TH, Ro J. Breast cancer subtypes and survival in patients with brain metastases. Breast Cancer Res. 2008; 10:R20.

24. Wiksyk B, Nguyen DH, Alexander C, Truong PT. Population-based Analysis of Treatment and Survival in Women Presenting With Brain Metastasis at Initial Breast Cancer Diagnosis. Am J Clin Oncol. 2014. [Epub ahead of print].

25. Minniti G, Esposito V, Clarke E, Scaringi C, Bozzao A, Lanzetta G, De Sanctis V, Valeriani M, Osti M, Enrici RM. Stereotactic radiosurgery in elderly patients with brain metastases. J Neurooncol. 2013; 111:319-25.

26. McDonald MW, McMullen KP. A new paradigm in treatment of brain metastases. Curr Probl Cancer. 2015; 39:70-88. 